\title{
UN ANÁLISIS CRÍTICO A LAS PRÁCTICAS CONTABLES IRREGULARES EN EMPRESAS DE DIVERSAS ACTIVIDADES
}

\author{
DR. CPC. ERNESTO POLAR FALCÓN
}

Docente de la Facultad

\begin{abstract}
RESUMEN
Se plantea cuatro objetivos, los dos primeros relacionados al análisis de la información periodística que ofrecen los artículos publicados en la página del "The Wall Street Journal Americas" del diario El Comercio de Lima, Perú y de dos artículos también publicados por el mismo diario, como única fuente disponible de investigación, ya que no se cuenta con bibliografia del tema, ni separatas que hayan comentado alguna parte del problema de irregularidades contables. Se fija el marco conceptual y el marco metodológico del estudio, que incluye el método histórico y el método hermenéutico, para conocer las acciones pasadas y buscar su explicación, respectivamente.

En el análisis del problema, se presenta un esquema histórico especifico: con fechas, títulos de los articulos publicados y un resumen de cada uno de ellos - La información obtenida es verdaderamente muy interesante y se van descubriendo una serie de situaciones de irregularidades contables, de posiciones empresariales diversas y de acciones frente a la justicia-.

Con este análisis, se precisan las causas que originaron las irregularidades contables y se canalizan por áreas para una mejor toma de conciencia y aplicación de futuras acciones concretas de cambios en el ámbito contable americano. Estos canales agrupan las causas profesionales, económicas, sociales y éticas.

Es importante también, mostrar la definición del marco conceptual como una aplicación de la Teoría General de la Contabilidad, para llegar al marco conceptual del IASB (International Accounting Standards Board) y a su análisis secuencial, que precisa las diferentes etapas de objetivos, hipótesis, requisitos, conceptos y criterios que sustentan la estructura de los estados financieros y la razonabilidad en la nformación que se entrega a los usuarios.
\end{abstract}

Se exponen alternativas para reforzar el mayor conocimiento de los principios de contabilidad y la necesidad de eliminar el nombre de contabilidad creativa y sustituirlo por el nombre de contabilidad engañosa, que fija con exactitud su espiritu de engaño, de defraudación, de hacer trampas, etc.

-as conclusiones de este artículo, plantean la necesidad de mejorar la imagen del Contador Público con un nuevo enfoque, llevándolo a practicar el juramento profesional al inicio de sus actividades en la 
profesión, siguiendo el ejemplo del Juramento Hipocrático de los médicos. Se enfatiza el mayor estudio de los princıpıos de contabilidad, el mejor conocimiento de la normatividad contable vigente. así como de los principios de ética profesional.

Palabras clave: Prácticas contables irregulares, ética profesional, corrupción.

\section{INTRODUCCIÓN}

El presente artículo ha tomado como base el Área: "1. Investigación Contable" del Temario Técnico de la 26 Conferencia Interamericana de Contabilidad. Específicamente, ofrece su aporte como una investigación en la Sub-Área: "1.1 Causas de las irregularidades contables y sus efectos en el desarrollo de la profesión". Toma como base el objetivo planteado en la Exposición de Motivos y las recomendaciones deincursionar, desde una perspectiva crítica, en los importantes aspectos relacionados con la actuación profesional, los marcos conceptuales de contabilidad y las propuestas de acciones concretas en el ámbito contable.

\section{A. OBJETIVOS DE LA INVESTIGACIÓN}

De acuerdo a los enunciados del párrafo anterior, los objetivos de investigación que se aplican en este artículo son los siguientes:

1. Analizar el contenido de la información periodística que ofrecen los artículos publicados en la página del The Wall Street Journal Americas del Diario El Comercio de Lima-Perú, que con un profundo espíritu de investigador, se ha recopilado en el período julio 2000 - junio 2002 , sobre las irregularidades contables más relevantes que se presentaron en los Estados Unidos.

2. Mostrar los resúmenes más saltantes del contenido de dos artículos periodísticos publicados en el diario El Comercio, Lima, Perú, en el mes de marzo de 2002, sobre las irregularidades contables del caso EN-
RON, entre ellas el uso de la contabilidad engañosa; asícomo algunas recomendaciones para mejorar los procesos de contabilidad y auditoría.

3. Ubicar en dichas informaciones periodísticas, como única fuente de datos que hemos tenido en el Perú, las causas que a criterio profesionaloriginaron esas irregularidades contables.

4. Proponer algunas acciones concretas que pudieran aplicarse en el ámbito contable de América, específicamente en el campo de los marcos conceptuales de contabilidad.

\section{B. MARCO CONCEPTUAL}

Se aplica el marco conceptual de uso de términos contables, de amplio conocimiento por todos los profesionales de la ciencia contable, tanto en el desarrollo de trabajos de investigación como en el trabajo profesional rutinario.

\section{MARCO METODOLÓGICO}

Los métodos específicos de investigación son aquellos que se emplean de acuerdo con el tipo de investigación que se realiza. En este artículo se aplica: el método histórico, que muestra el camino para llegar al conocimiento del tema planteado, por medio del estudio de acontecimientos ocurridos en el pasado; y el método hermenéutico que analiza e interpreta los resultados que se obtienen de tales acontecimientos. 


\section{CONTENIDO DE LA INFORMACIÓN PERIO- DISTICA RECOPILADA DEL THE WALL STREET JOURNAL AMERICAS}

El proceso de recopilación de la información periodística se inició en el mes de julio de 2000 y termina en julio de 2002. De cada artículo publicado se muestra lo siguiente:

- Fecha del artículo.

- Titular del artículo.

- Un breve resumen de los problemas que son importantes mostrar para ubicar las causas de las irregularidades contables que se han ido presentando en el proceso histórico que se describe.

Los breves resúmenes de los artículos publicados, permiten puntualizar específicamentelos problemas. La publicación completa de cada artículo produciría un voluminoso contenido de páginas. Sin embargo, para los investigadores deseosos de profundizar estudios del tema, los artículos publicados pueden ofrecerse posteriormente como información adicional.

\section{DIARIO EL COMERCIO, LIMA, PERÚ}

Pagina: The wall street journal americas. resúmenes de los articulos publicados

\section{AÑO 2000 - ANTECEDENTES SOBRE OPERACIONES DE AUDITORIÁ Y CÓNSULTORIAA}

1. 14 julio 2000 - La suerte de las Andersen en manos de un árbitro colombiano

Contadores: Arthur Andersen - Consultores: Andersen Consulting - Supervisor: Andersen Worldwide - SEC propone normas para reducir conflictos de intereses - Decisión final del Árbitro en la Corte Internacional de Arbitraje de París - Facturación en 1999: Contadores US\$ 7200 mill. - Consultores: US\$8900 mill. - Trabaja- dores: 135000 - Contadores empezaron su propio negocio de consultoría - Mayor facturación de consultores - Pago de US\$ 1000 mill. de consultores a contadores.

2. 08 agosto 2000 - Una victoria parcialpara los consultores en el divorcio de andersen y andersen

Ordena pago de US $\$ 1000$ mill. - Consultores: independencia total y uso de nombre hasta el cierre de año - Andersen Worldwide: criticada por falta de supervisión a afiliadas-SEC: Nuevas normas para separar operaciones de auditoría y consultoría - Contadores estaban compitiendo por clientes de su propia compañía hermana - Pagos anuales a contadores muy irritante para los consultores.

\section{AÑO 2001 - UN CASO DE FRAUDE CONTABLE}

1. 05 abril 2001 - Arrestos en un caso de fraude a cientos de inversionistas latinos

InverWorld Inc.: Quebrada firma de valores - Recuperar cientos de millones de dólares - Arrestados: Presidente del Directorio - Acusados de defraudar a los inversionistas US $\$ 325$ mill. entre 1993 y 1995 - Plan de fraude: Tipo Pirámide - Reclutar nuevos clientes para repagar a inversionistas y cubrir gastos operativos - Contadores y abogados actuaron indebidamente-Informes: $50 \%$ de activos eran ficticios - Demanda de inversionistas a contadores y abogados por no detectar actividades ilegales y permitir que fraude continuara.

\section{AÑO 2002 - CASOS ENRON / ARTHUR ANDESERN}

\section{29 enero 2002 - Grandes contables en supropia} revisión

A pesar de detectar grandes errores, se daban unas a otras credenciales de buena 
salud-Revisiones recíprocas entre las cinco grandes firmas de contabilidad.

2. 29 enero 2002 - Los derivados, en la mira de reguladores

Usos de derivados y sociedades fueta de libros para esconder pérdidas en acciones tecnológicas y deudas en negocios no rentables.

3. 29 enero 2002 - Delta podría romper con Andersen

Setía la deserción más importante desde que se destapó el escándalo ENRON - Busca nuevo auditor-En el año 2001 Delta pagó a Arthur Andersen US\$1 920000 por servicios de auditoría y US\$3970000 en otros honotarios.

4. 30 enero 2002 - El contagio de los escándalos contables crece y los mercados de valores caen

Temor por los libros de las empresas - Las acciones de EE.UU. cayeron drásticamente por los problemas contables de ENRON.

5. 30 enero 2002 - El analista que rebajó a ENRON y fue despedido

Fue antes del colapso y BNP Patibas tenía otros negocios con la compañía - Los papeles de ENRON deberían ser vendidos a cualquier costo y ahora mismo - agosto 2001 - En Bolsa de Nueva York : julio 2001 - US $\$ 50.00$ - agosto 2001 - US\$38.00 - enero 2002 -US\$0.67.

6. 30 enero 2002 - ¿Podrá ubs traer de vuelta a los clientes?

Se tiene que ganar a los clientes uno a uno - UBS ofreció pagar en efectivo a ENRON por sus operaciones de comercialización y royalties por corretaje energético.

7. 30 enero 2002-Escándalos recientes en EE.UU. camibian el papel de las juntas directivas Junta Directiva de ENRON semantuvo en tinieblas por sus directivos y sus auditores
Arthur Andersen y no supo problemas contables hasta octubre 2001.

8. 30 enero 2002-MERRILL-ENRON: iun conficto de intereses?

Metill desempeñó varios papeles en $\mathrm{EN}$ RON: Agente colocador - prestamista - inversionista - 100 Ejecutivos de $\mathrm{Me}$ rrill invirtieron más de US\$ 16 mill. de su propio dinero en una sociedad que se vendía a ENRON.

9. 31 enero 2002 - La FED deja intactas las tasas Pero los casos de auditoría amenazan el optimismoeconómico-FED: Punto final a su larga campaña de recorte de tasas de interés justo - Crisis en la confianza desencadenada por el caso ENRON.

10.31 enero 2002 - Abora, las dudas contables le tocan a otra sociedad de auditoría y consultoría

Otta de las cinco grandes firmas de contabilidad atrapada en interrogantes contables como consecuencia del caso ENRON.

\subsection{5 febrero 2002 - Washington investiga ciertas} operaciones de ENRON

Transacción en acciones de ENRON en una de sus sociedades que no fueron registradas en su balance - El 20 de enèro de 2000 , las acciones de ENRON subieron $26 \%$ en un día; de US\$ 53.50 a US\$67.38.

12.21 febrero 2002 - Artbur Andersen frece cientos de millones a los a los acreedores de ENRON

La medida se tomó para evitar costosos litigios en el futuro - Negociar un acuerdo universal con accionistas, acteedores y empleados de ENRON con una oferta entre US\$700 millones y US\$800 millones.

13.04 marzo 2002 - Aislada entre las firmas contables

El sector, inquieto, se distancia de Arthur Andersen-Las principales firmas de audi- 
toría y la asociación que las agrupa se han distanciado de Arthur Andersen - Una coalisión de la industria contable está preocupada; esta situación está empañando la capacidad del grupo para hacer lobby ante el Congreso de Estados Unidos - Su papel como auditor está siendo investigado por el Departamento de Justicia y por la Comisión de Bolsa y Valores - Arthur Andersen nombra a Paul Volcker, ex presidente de la Reserva Federal de EE.UU, para encabezar el comité que evaluará las operaciones de la firma y recomendará amplia reformas.

14.08 marzo 2002 - ENDES A vuelve a sus raices

Su Presidente ejecutivo dice que ENRON ha cambiado la forma de hacer negocios - Tiene planes para concentrar sus energías en su negocio principal: la generación y distribución eléctrica.

15.08 marzo 2002 - ENRON desató una ola de reformas y propuestas, ¿ serán duraderas?

Las grandes corporaciones adoptan la transparencia. Nadie se conforma con menos - El derrumbe de ENRON ha llevado a todas las empresas a dejar de lado los malos hábitos contables y transparencia de la información - Junta de Normas de Contabilidad Financiera (FASB) : cambio en sociedades que no se incluyen en libros contables - Los contadores no son suficientemente rigurosos por temor a perder lucrativos honorarios por servicios de consultoría.

i6.1 marzo 2002 - Victima de la resaca de ENRON, Andersen anda buscando un paladin que la compre

Corteja una sociedad de auditoría y consultoría y otras firmas contables para que compren la totalidad o parte del negocio - Busca despertar el interés de compra
- Desea negociar con fiscales federales los cargos a presentar - La quinta firma más grande de EE.UU., pilar del sistema financiero con más de 2300 clientes de auditoría.

17.12 marzo 2002 - Volcker anuncia reformaspara Andersen

Pero la investigación federal y la posible venta ganan impulso - El ex-presidente de la FED recomienda que se separen los negocios de contabilidad y asesoría para evitar posibles abusos.

18.12 marzo 2002 - Los contadores que contaron demasiado

Andersen perdió de vista sus responsabilidades de auditoría al buscar mayores riquezas como consultores - Para Arthur Andersen, nadie iba a enriquecerse sólo haciendo auditorías - Para que los socios participaran de los cientos de miles de dólares, se tenía que impulsar el lucrativo negocio de consultoría - Por la mayor parte de la segunda mitad del siglo XX, una opinión de auditoría de Andersen era vista como la norma de oro de la industria.

\subsection{4 marzo 2002 - El tiemposeh}

Las esperanzas de evitar una acusación o de fusionarse con un competidor para frenar la destrucción parecen diluirse - Departamento de Justicia se disponía a formular cargos de obstrucción de la labor dela justicia-Conversaciones con diversas firmas competidoras para fusionarse.

20.14 marzo 2002 - ¿Se convertirán las cinco en cuatro?

La puesta en venta de Arthur Andersen representa una oportunidad poco común para que sus rivales contables se queden con activos valiosos a precios económicos. 
21.15 marzo 2002 - La acusación criminal de Washington reduce las opciones de Artbur Andersen

Fiscales criminales acusaron a la quinta mayor firma contable de EE.UU. del delito de obstrucción a la justicia.

22.18 marzo 2002 - Abora viene la parte dificil: probarlas acusaciones contra Arthur Andersen

Se tiene que probar no sólo que Andersen persuadió a sus empleados a destruir documentos relacionados con las auditorías a ENRON-Se tiene que probar la culpabilidad de individuos de Andersen lo suficiente para involucrar a la firma.

23.19 marzo 2002 - Andersen está cerca de vender. sus oficinas internacionales a una sociedad de auditoría y consultoria

Así lo comunicaron en forma conjunta - Las negociaciones que comenzaron hace algún tiempo, involucran las operaciones en Latinoamérica.

24.20 marzo 2002 - Andersen: se complica la transacción con una sociedad de auditoría y consultoria

Posibles obstáculos: Pérdidas de empleos y obligaciones pensionables en algunos países. La Comisión Europea en otras autoridades con objeciones antimonopolio. Acuerdos país por país.

25.20 marzo 2002 - Cuentas dudosas el efecto Enron en Latinoamérica

La crisis tiene un costado positivo, al poner sobre la mesa la necesidad urgente de reformas - Mientras la tormenta contable en Estados Unidos sigue causando estragos en el mundo empresarial, América Latina, e incluso España, ha decidido hacer un alto en el camino y revisar las prácticas contables - El primer gran ejemplo es el conflicto de interés de los contadores. En casi toda
América Latina no se prohibe a las firmas ar contabilidad prestar servicios de auditona asesoría a una misma empresa - En America Latina y España sólo se encontraron 2 excepciones: Brasil y Colombia - Suele decirse en la región que las empresas mantienen tres libros: uno para el departamento de impuestos, otro para los accionistas y un tercero con la verdad.

26.21 marzo 2002 - Crisis para todos, ain socios no ligados a $E N R O N$

Muchos invirtieron su propio dinero para ascender, pero ahora lo pierden todo - Como todas las cinco grandes firmas de contabilidad de los EE.UU., Andersen exige a sus socios poner dinero en la firma cada año (entre US $\$ 50000$ y US $\$ 250000$ dependiendo de la antigüedad, salario $y$ otros factores)-Es un duro golpe para los 85000 empleados alrededor del mundo y, especialmente; traumático para sus 4700 socios, la mayoría de los cuales no tenían nada que ver con ENRON.

27.21 marzo 2002 - Andersen contra ataca

La firma logra un pronto juicio y lanza campaña de defensa - Arthur Andersen obtuvo una fecha de juicio temprana, lo que podría darle una posible ventaja en su batalla con el Departamento de Justicia de Estados Unidos para evitar ser condenada.

28.25 marzo 2002 - Ex socio puede perjudicar la defensa legal de Andersen

Ex auditor principal de Arthur Andersen en la cuenta de ENRON, se reunió la semana pasada con los fiscales federales para discutir la posibilidad de cooperar en el caso criminal del gobierno contra Andersen.

29.27 marzo 2002 - El aroma a escándalo convierte a los contadores en los reyes de la fiesta

Un libro publicado: Eljuego de números financieros: Detección de prácticas contables creativas 
- Otto libro publicado: Chanchullos financieros: Cómo detectar ardides contables y fraudes en informes financieros - Un dicho: "Ser contable le da un cierto aire de peligro".

30.27 matzo 2002 - Tras dimisión de sujefe, Andersen planea venta

El presidente ejecutivo anunció su renuncia, mientras la firma de contabilidad, sigue adelante con las conversaciones para vender sus operaciones en EE.UU. que no son de auditoría por más de US $\$ 1000$ millones.

31.27 marzo 2002 - Las opciones sobre acciones, bajo asedio

Las empresas en EE.UU. se reunieron en una causa común: salvar las opciones sobre acciones que dan a los trabajadores una pałticipación financiera del éxito de sus compañías - El presidente de ENRON obtuvo US $\$ 123,4$ millones al hacer efectivas sus opciones de compra de acciones en 2000. En contraste, la mayoría de accionistas perdieton el grueso de su inversión en ENRON y miles de trabajadores de la gigante energética perdieron sus trabajos y sus ahorros de jubilación.

32.28 marzo 2002 - La cúpula de Andersen batalla por retener a los socios de la firma

Los principales ejecutivos de Arthur Andersen están luchando por unir a un grupo de socios que está cada vez más dividido.

33.03 abril 2002 - Deserción de españa amenaza la solución global de Andersen

Caminos separados - Las oficinas de Andersen en el mundo están ansiosas de realizar funciones - La muy cotizada filial española acordó fusionarse con importante firma de contabilidad - La mayoría de socios de Andersen en Latinoamérica seguirán el ejemplo de los españoles.
34. 04 abril 2002 - Wasbington estaria dispuesto a llegar a un acuerdo extrajudicial con Andersen

A cambio, la firma reconocería haber destruido documentos relacionados con ENRON - El Departamento de Justicia está dispuesto a considerar un acuerdo extrajudicial de su acusación penal porobstrucción de la justicia, si la firma, de alguna manera, admite que "destruyó ilegalmente documentos".

35.04 abril 2002 - Consultoría y auditoría se resisten al divorcio a pesar del caso ENRON

¿Cuán objetiva puede ser una firma de contabilidad en una auditoría cuando también gana millones de dólares dando otros servicios al mismo cliente? - ¿No tienen esos auditores un incentivo para ser condescendientes? - Las firmas de contabilidad niegan enfáticamente que la integridad de sus auditorías esté comprometida. Dicen que generalmente una auditoría puede verse mejorada por el conocimiento complementario que una firma de contabilidad tiene de un cliente que también conoce a través de su brazo consultor.

36.05 abril 2002 - Ese algo intangible que bace más vulnerable a las empresas

Cuando Winster Co. Inc., se acogió a la protección de la bancarrota en abril pasado dijo que sus activos ascendían a US $\$ 5000$ millones. Se incluía una ted de telefonía y servicio de Internet a 60 unidades. Luego sus activos se vendieron por US $\$ 42 \mathrm{mi}-$ llones - Presidente de la Reserva Federal: "Una firma es inherente frágil si su valor agregado emana más de lo conceptual que los activos físicos".

37.05 abril 2002 - Andersen lograria salvar poco, aún sipactara con WWashington

Su red mundial se desintegra y nada podtá restaurar su reputación - En resumen, las 
"cinco grandes" serán ahora cuatro jugadores en el negocio mundial de la contabilidad.

38.05 abril 2002 - La crisis de Andersen, una oportunidad

El desplome beneficia a sus rivales, que tienen capacidad ociosa - Frases de ejecutivos de firmas de contabilidad:-Todas las firmas tienen capacidad ociosa-. "Tenemos la capacidad de asumir los clientes que estamos ganando"-Frase de un ejecutivo de una empresa: "Todas las firmas buscaron agresivamente obtener nuestra cuenta".

39.12 abril 2002 - Andersen ultimó trato con el gobierno de EE.UU.

La firma no ha aceptado aún reconocer que obstaculizó la justicia - Intenta ultimar detalles de un acuerdo para resolver una acusación criminal del gobierno y las demandas civiles de los accionistas y acreedores de ENRON.

40.17 abril 2002 - Elcongreso de EE.UU. apunta sus dardos contra J. P. Morgan

Los investigadores del Congreso de EE.UU. están dirigiendo su mirada hacia J. P. Morgan Chase \& Co. por sus conexiones con ENRON.

41.17 abril 2002 - Obstáculos a un arreglo con Andersen

Surgen problemas con sus acreedores y nuevas acciones legales - Dos nuevas disputas, que involucran a los acreedores de ENRON y el reclamo de un fiscal general estatal amenazan con obstaculizar un posible arreglo con el Departamento de Justicia de los EE.UU.

42.17 abril 2002 - ¿Podrá sobrevivir Andersen?

Será una firma más pequeña que sólo realiza auditorías-Portavoz de Andersen: "Habrá sólidas auditorías y la experiencia necesan en impuestos para brindar un servicio ae auditoría de primera. Estamos marchando adelante agresivamente con nuestr plan".

43.27 junio 2002 - Worldcom pone en jaque a los mercados

Nuevo escándalo contable sacude la confianza de los inversionistas

Contabilidad Creativa:

WorldCom

- Registro de US\$3055 millones. Los US $\$$ de gastos para finalizar como de capital.

- Amortiza US\$3055 millones en períodos de 3 a 10 años.

- Declara una ganancia neta de US\$1380 millones en 2001.

P.C.G.A.

- Los 3055 millones en gastos de completar llamadas se registran como gasto operativo.

- La totalidad de los US\$3055 habrían sido contabilizados como un costo de negocios para ese trimestre

- La ganancia neta para 2001 habría sido una pérdida.

44.17 julio 2002 - Fraudes contables: la nueva asignatura en la universidad

Clases de Cocina:

Cursos nuevos que ofrecen algunas universidades de EE.UU.

- "El caso ENRON"

- Universidad de California en Irvine

- "La Escuela Contable"

- Universidad de Notre Dame 
- "Problemas de Contabilidad"

- Universidad de Texas en Austin

- "Las Lecciones de ENRON"

- Universidad de Washington y Lee

Opinión de profesor emérito de Baruch College de Nueva York: "El problema de la educación contable es que los profesores piensan que lo suyo tiene que ver con una investigación científica de alto nivel. Desarrollan modelos matemáticos esotéricos cuando en realidad deberían poner manos a la obra y enseñar a los alumnos a entender los informes trimestrales y anuales de las compañías"

AÑO 2005 - EPILOGO: CONDENA JUDICIAL A EJECUTIVO

1. 15 abril 2005 - La condena del ex jefe de worldcom, mal augurio para ejecutivos que esperan juicio

Presidente de WorldCom fue declarado culpable de participar en el mayor fraude contable de la historia de Estados Unidos, dándole al gobierno de ese país, una victoria memorable en su esfuerzo por juzgar a los responsables de escándalos corporativos. El fraude contable fue por US $\$ 11000 \mathrm{mi}$ llones. Enfrenta 85 años de prisión-Edad: 63 años.

\section{AÑO 2005 - EPILOGO: CORTE SUPREMA DE EE.UU. REVOCA CONDENA A A. ANDERSEN}

E1 junio 2005 - Decisión judicial reinvidica a Andersen, pero probamente no revertirá su fortuna

L. Corte Suprema de Estados Unidos habría rertido ayer la condena contra la empresa
- "Esta decisión es buena para el legado de Arthur Andersen" - "Esta es una reinvidicación de la mayoría de los que encarnamos la visión y los valores de la venerable organización, pero no de los pocos gerentes que permitieron la destrucción de Andersen"-La Corte Suprema revocóla condena de la firma contable en 2002, en el caso vinculado a sus fallidas auditorías de ENRON e indicó que los jurados usaron pautas de culpabilidad demasiado laxas con Andersen, antaño una venerable firma de contabilidad-Hasta cierto punto, se ha eliminado un estigma.

\section{E. CONTENIDO DE LA INFORMACIÓN PERIODISTICA RECOPILADA DE EL COMERCIO, LIMA, PERÚ}

En el diario El Comercio, Lima-Perú, se publicaron dos artículos cuyo resúmenes son los siguientes:

\section{12 marzo 2002 - Etica y negacios}

Enseñanzas del caso ENRON - La estrepitosa quiebra de la Corporación ENRON ha distorsionado los mercados mundiales desde sus cimientos hasta el punto de que para muchos analistas económicos sus efectos son comparables a los generados el 11 de septiembre de 2001 - La contabilidad engañosa fue concebida por una organización vinculada a la auditora que luego validaba los balances - Urge adoptar una ética más sólida en el mundo de los negocios en la que el fin no justifique los medios y desterrar esas maniobras legales con las que se engaña a los accionistas, a los organismos reguladores y al Estado.

2. 25 marzo 2002 - Malas prácticas contables: el caso ENRON Corp.

$\mathrm{El}$ mercado financiero internacional ha quedado pasmado con el debate del gigante energético ENRON CORP., a quien inclu- 
so el Gobierno Estadounidense tomaba como ejemplo eficiente y de sanas prácticas corporativas - Con activos superiores a US $\$ 60$ mil millones y valor de cotización al alza en los últimos años, ENRON experimentó en un año una caída en el precio de sus acciones de 86 dólares / acción a menos de 0.50 dólares / acción-ENRON reconoció públicamente después de la intervención de la SEC, que había cerca de US $\$ 600$ millones que "inflaban" las utilidades de los últimos cinco años - Se estiman pasivos por más de US $\$ 40000$ millones en fondos de inversión, de terceros, bancos, proveedores, Gobierno y empleados, gran parte de los cuales irrecuperables.

\section{Resumen de comentarios}

¿Cómo ocurrió esta situación si existieron auditorías externas que avalaban la situación económica de la empresa? - En este tema hubo cierta laxitud al permitirse que empresas auditoras hicieran también el "outsourcing" contable en las mismas organizaciones, es decir poner al gato de despensero.

4. Es importante mostrar las recomendaciones contables del artículo

- Realizar una reingeniería para establecer de acuerdo al sector económico de la empresa cierto tipo de información mínima relevante.

- Revisar las normas contables de auditoría.

- No permitir que empresas auditoras realicen en forma paralela el "outsourcing" contable en la misma empresa o en empresas del grupo.

- Revisar los procedimientos de auditoría a efectos de corregir los puntos de control que necesiten ser sometidos a mayor rigurosidad.
- Las empresas deberían considerar la opción de mantener una sociedad auditora por un determinado número de años-Se debe inculcar en las empresas y ejecutivos las normas de ética y valores corporativos que van más allá de las metas financieras.

\section{F. CAUSAS QUE ORIGINARON IRREGU- LARIDADES CONTABLES}

Tomando en cuenta el esquema histórico que se presenta, se pueden precisar las causas que originaron las irregularidades contables, específicamente en el período de enero-julio 2002 , en base al estudio de los artículos periodísticos publicados, única fuente de información que estuvo mostrando casi día a día la debacle económica y financiera de algunas empresas de los EE.UU. y de una firma internacional de contabilidad con sus oficinas principales en dicho país.

Las causas que se presentan a continuación, han sido canalizadas por áreas afectadas por las irregularidades contables, que se han mostrado, para una mejor toma de conciencia en la aplicación de futuras acciones concretas de cambios en el ámbito contable americano:

\section{CAUSAS}

\section{PROFESIONALES}

- No registrar determinadas operaciones en libros contables de la empresa para esconder pérdidas, deudas y beneficios económicos.

- No alertar a ejecutivos probos de posibles caídas estrepitosas del valor de las acciones.

- No informar adecuadamente los problemas económicos y financieros a las juntas directivas de las empresas. 
- No comunicar a los directivos de la empresa, de las acciones ilícitas que cometen personas o empresas afiliadas, que desestabilizan las operaciones normales del negocio.

- No mantener un riguroso control de usosy aplicaciones correctas de los principios de contabilidad, por temor a perder lucrativos honorarios en consultoría.

- No protestar profesionalmente cuando se comenta que las empresas preparan 3 juegos de libros contables: uno para el control de los impuestos, otro para los accionistas y otro que dice la verdad.

- No aceptar operaciones contables en el marco de la mal llamada contabilidad creativa.

\section{ECONÓMICAS}

- Ofrecer servicios de auditoría y consultoría simultáneamente a una misma empresa.

- Perder de vista las responsabilidades de auditoría , por buscar mayores riquezas en consultoría.

- Invertir su propio dinero para ascender a cargos ejecutivos que brindan mayores ingresos.

\section{SOCIALES}

- Participar en delitos de fraude cometidos por altos ejecutivos de empresas.

- Perder la confianza de la sociedad ante el temor de procesar libros contables fraudulentos.

- Proponer actividades transparentes en los negocios, solamente cuando se detectan malos hábitos contables y financieros.

- Buscar personalidades de entidades del gobierno o de instituciones de prestigio, para que solucionen problemas creados por irregularidades contables.

- Realizar delitos de obstrucción a la justicia para que detecte las irregularidades contables, económicas y financieras.

- Decidir revisiones de prácticas contables, cuando las noticias informan de problemas graves ocurridos en empresas.

\section{4. ÉTICAS}

- Otorgarse credenciales de aprobación entre contadores por trabajos profesionales de dudosos resultados.

- Colaborar con trabajos profesionales adicionales en empresas con problemas de auditoría y consultoría.

- Ofrecer dinero a inversionistas y empleados de una empresa para evitar denuncias por actos ilícitos cometidos.

- Realizar acciones agresivas para captar clientes de una empresa de contabilidad con problemas.

\section{G. LA ACTUACIÓN PROFESIONAL FRENTE A LAS IRREGULARIDADES CONTABLES ANALIZADAS}

Un marco conceptual, puede definirse como una aplicación de la Teoría General de Contabilidad en la que, mediante un itinerario lógico deductivo, se desarrollen los fundamentos conceptuales en los que se basa la información financiera, al objeto de dotar de sustento nacional a las normas contables -El seguir un itinerario lógico deductivo implica que cada uno de los escalones contemplados en el mismo es congruente con los anteriores, lo cual refuerza la racionalidad del producto final.

En base a este planteamiento, el marco conceptual del IASB (International Accounting Standars Board), analiza secuencialmente: 
- La definición de los objetivos de la información financiera, en congruencia con las necesidades de los usuarios.

- La formulación de dos hipótesis, empresa en funcionamiento y devengo (Del verbo devengar: adquirir, ganar), como normas fundamentales de funcionamiento del sistema contable destinado a la elaboración de información financiera con propósitos externos.

- El establecimiento de sus requisitos o características cualitativas, necesarios para asegurar que la información financiera cumple con sus objetivos.

La definición de los conceptos que integran los elementos básicos de los estados financreros: activos, pasivos exigibles, fondos propios, gastos e ingresos.

- El establecimiento de los criterios de reconocimiento de estos elementos, cuyo cumplimiento es necesanto para que puedan incluirse en los estados financieros.

- Los criterios que puedan utilizarse en la valorización de tales elementos de los estados financieros.

Los criterios básicos que rigen el mantenımiento del capital y su incidencia en el concepto de resultado.

Por lo tanto, en base a las irregularidades contables presentadas en este trabajo, se puede afirmar, que en un período no determinado, que culminó en el año 2002, en los EE.UU, algunas empresas comerciales y de servicios, así como algunas firmas de contabilıdad, no aplicaron este marco conceptual fundamental, lo que orıginó el debacle económico y financiero ya conocido.

Que es necesario, reforzar el mayor conocimiento y uso de los principios de contabi- lidad y modificar las normas que pudieran haber sido afectadas, para evitar que se repitan estas irregularidades contables.

Que se proponga a nivel americano suprimir el uso de las palabras: "contabilidad creativa" por su efecto distorsionante, en base al siguiente razonamiento: $\mathrm{El}$ diccionario dice que el adjetivo "creativa" se interpreta como "que crea"; y el verbo "crear" indica: producir una cosa que no existía. Entonces "contabilidad creativa" se definiria como aquella contabilidad que produce cifras o partidas que no existían anteriormente; motivando así a practicarla en perjuicio de terceros y provocando las irregularidades contables que se trata de combatir.

- Es mejor usar las palabras "contabilidad engañosa". El diccionario dice que el adjetivo "engañosa" se interpreta como "que engaña"; y el verbo "engañar" indica: hacer caer en error y cuyos sinónimos son: mentir, embaucar, engatusar, defraudar, hacer trampas, etc.

\section{CONCLUSIONES}

Los resúmenes de los artículos publicados en la página: The Wall Street Journal Americas, en el diario El Comercio, Lima, Perú, así como los dos artículos de este mismo diario; relacionados con las irregularidades contables en algunas empresas de EE.UU. y de una firma de contabilidad internacional, han sido útiles para servir como fuentes de información y conocer solamente una parte de los problemas económicos y financieros que se produjeron, sin poder identificarse sus respectivos períodos de conflicto de intereses.

Es importante también mencionar que el contenido de los artículos fueron escritos por periodistas, que hubieran podido estar afecta- 
dos por los problemas que mostraban o quizás parcializados a uno u otro sector. Sin embargo, entregaron una buena información que ha sido debidamente captada en el presente artículo.

Las causas que originaron las irregularidades contables, se ha listado por áreas, de las cuales se extraen los siguientes comentarios:

- Se hizo caso omiso al buen uso de los principios de contabilidad. El desarrollo de una "industria de contabilidad" en los EE.UU., avasalló el servicio profesional de contabilidad. Este fenómeno social y económico, seguramente se mantiene en este país, por la magnitud de sus operaciones comerciales, industriales y de servicios. En los países en desartollo de América, por sus limitadas economías, se presume que no se presenta este fenómeno social y económico.

- Se dio mucha importancia a los aspectos judiciales en los EE.UU., con despliegue de noticias que involucraban a los acusados y a las instituciones de control financiero y de justicia, quizás algunas veces con enfoques políticos. El resultado de todo el proceso judicial finaliza cuando se anuncia que la Corte Suprema de EE.UU. ha revertido la condena contra Arthur Andersen, tal como se lee en un corto artículo publicado el 01 de junio de 2005.

\section{RECOMENDACIONES}

Tomando en cuenta la necesidad de proponer acciones concretas en el ámbito contable, a continuación se proponen las siguientes recomendaciones:

Desarrollar una nueva imagen profesional del Contador Público, que pueda iniciarse en la incorporación a su institución profesional, prestando un juramento de integridad personal y profesional, con la misma filosofía del Juramento Hipocrático que hacen los médicos. Este juramento no existe en la profesión contable y la falta del mismo, podría ser la causa de tantas irregularidades. Este juramento debería también tener un nombre y la Asociación Interamericana de Contabilidad ser su gestora, propulsora y fiscalizadora de su aplicación en toda la América. En este campo tiene cabida el marco conceptual de IASB, con escasa difusión entre Contadores Públicos.

2. Difundir con mucha fuerza el mayor estudio y el mejor conocimiento de la normatividad contable vigente. Así como de los principios de ética profesional relacionados con las actividades profesionales del Contador Público.

\section{REFERENCIAS}

The Wall Street Journal Americas - Informaciones periodísticas - 2000/2006.

El Comercio- 2000/2006.

Ley: Sarbanes - Oxley, Acta de 2002 - Cámara de representantes de los Estados Unidos de Norteamérica.

XXVI Conferencia Interamericana de Contabilidad - 26 CIC - 2005 - "Restaurar la confianza: hacia una transformación de los paradigmas vitales" - Área 1 - Investigación contable - 1.1. Causas de las irregularidades contables y sus efectos en el desarrollo de la profesión".

XIX Congreso Nacional de Contadores Públicos del Perú - Temario: 2004.

XX Congreso Nacional de Contadores Públicos del Perú - Temario: 2006.

I Convención Nacional de Ética y Ejercicio Profesional-2006 "Promoviendo la ética en la profesión contable y recuperando la confianza para una eficaz defensa profesional". 
Informativa - Responsabilidad penal de los contadores - 2004 - Unidad de Biblioteca - Facultad de Ciencias Contables - UNMSM.
Quipukamayoc - Revista de Investigación Facultad de Ciencias Contables - UNMSM - Artículos sobre Ética Profesional 